Sheffield

Hallam

University
Centre for

Regional Economic

and Social Research
Derbyshire
Law Centre

\title{
Just in Time Evaluation Report
}

May 2021

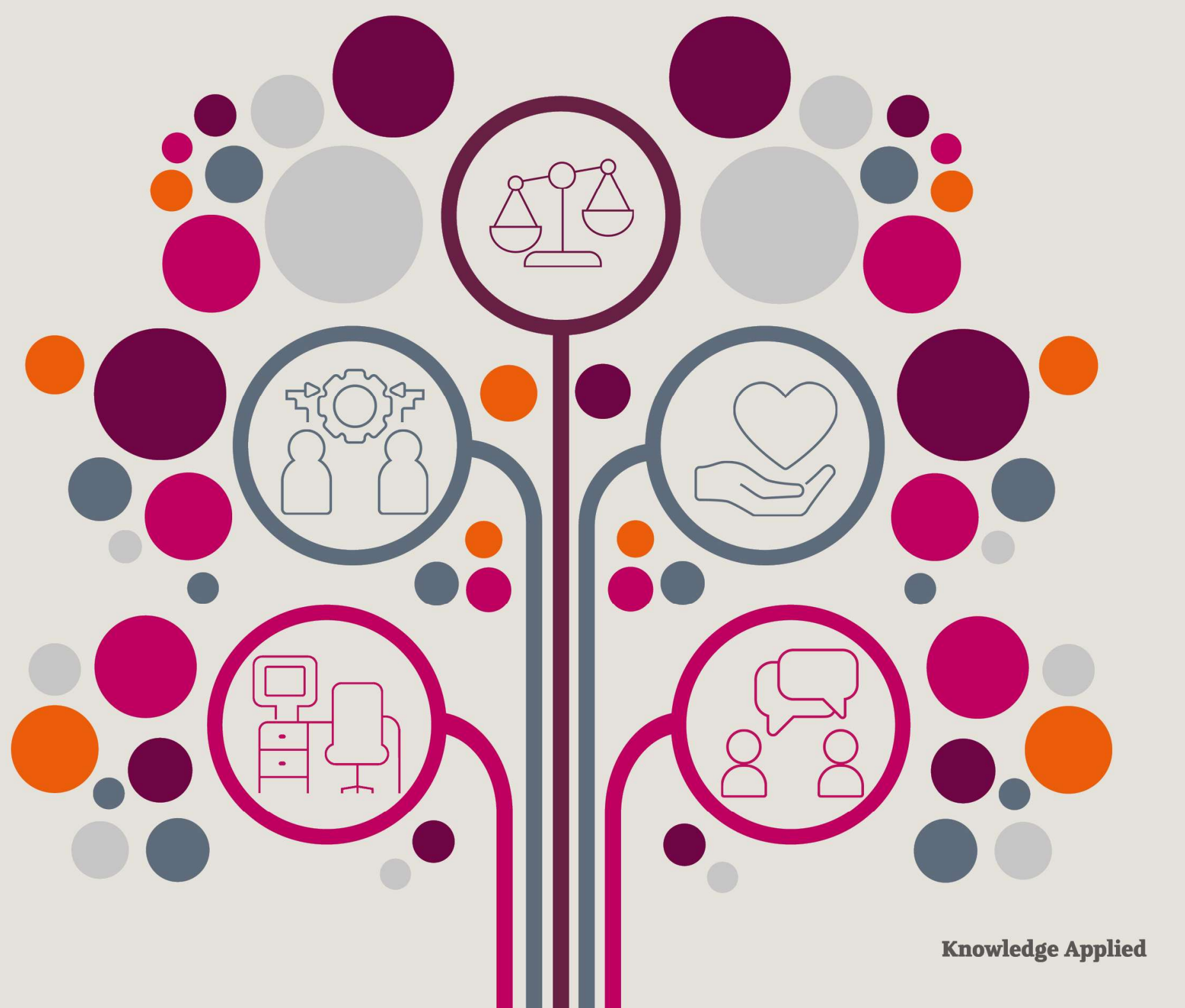




\section{Just in Time Evaluation Report}

\section{Authors:}

Richard Crisp

Jan Gilbertson

Elizabeth Sanderson

Abi Woodward

May 2021

DOI: $10.7190 /$ cresr.2021.8979011579 


\section{Acknowledgements}

The authors would like to thank the staff at Derbyshire Law Centre and wider stakeholders who contributed to and supported the evaluation. We are particularly grateful to the clients supported by the Just in Time project who gave up their time to talk about their experiences. 


\section{Contents}

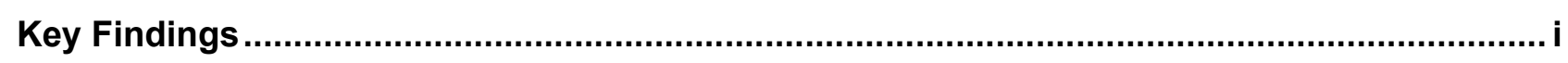

1. Introduction

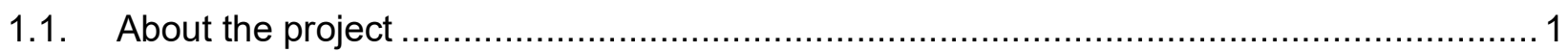

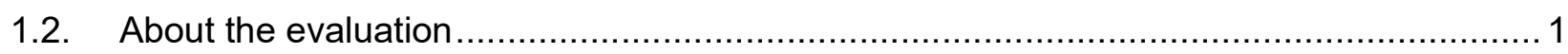

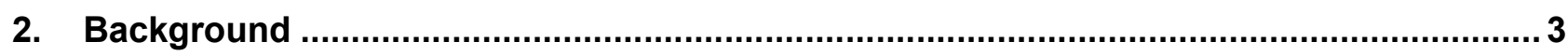

2.1. The relationship between work, health, and legal issues .......................................... 3

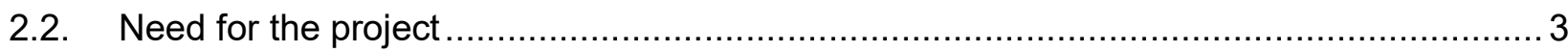

3. Who has been supported by Just in Time? …………...............................................

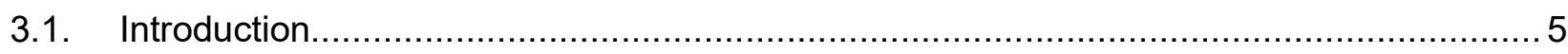

3.2. Clients supported

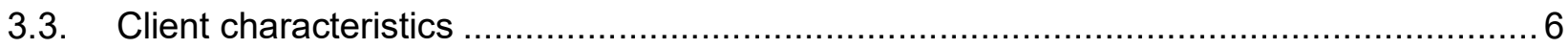

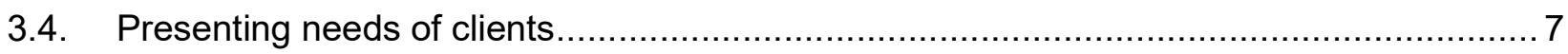

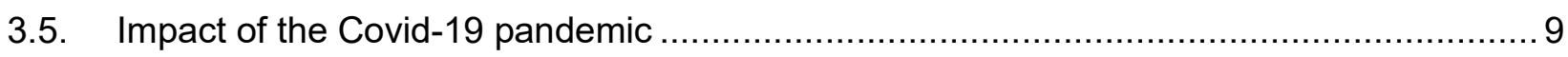

4. How has Just in Time been delivered? ........................................................................ 11

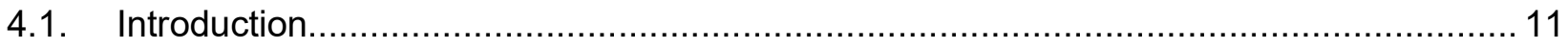

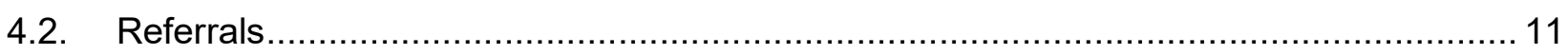

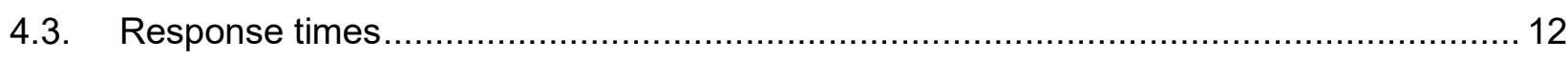

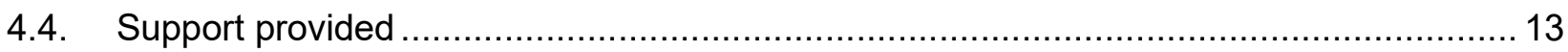

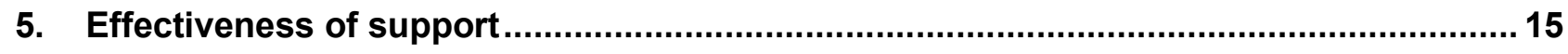

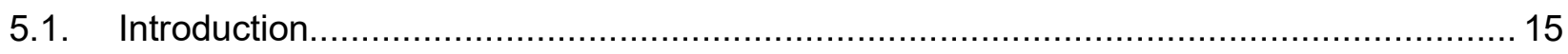

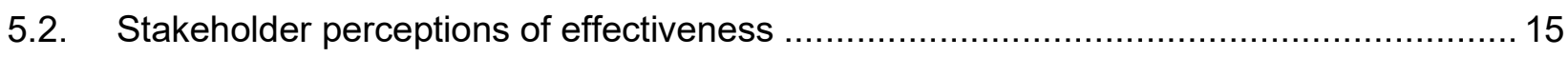

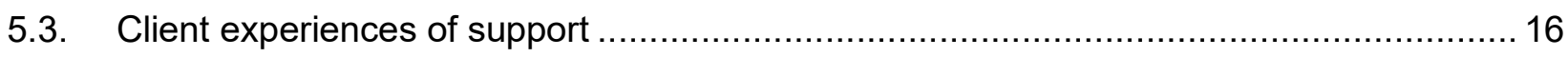

6. Outcomes achieved: stakeholder assessment............................................................... 19

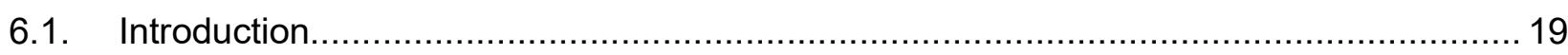




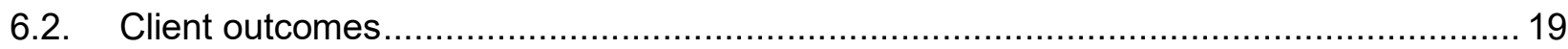

6.3. Employer practices and workplace cultures ............................................................ 21

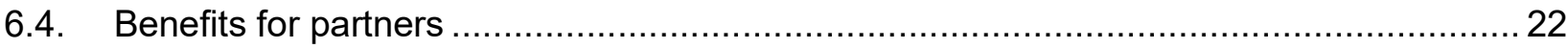

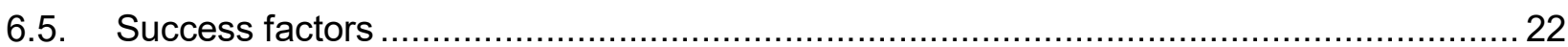

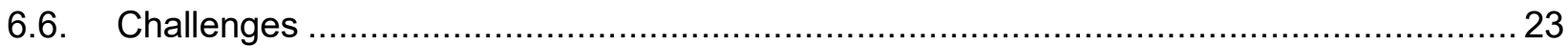

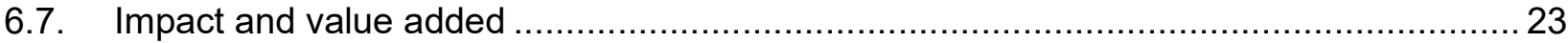

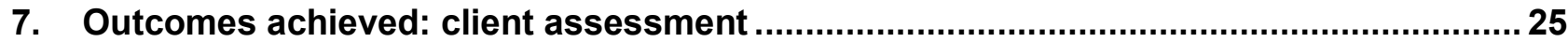

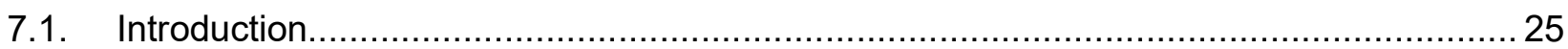

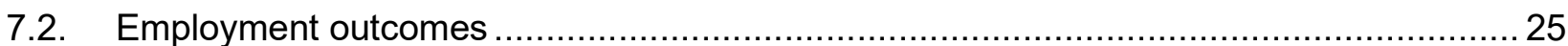

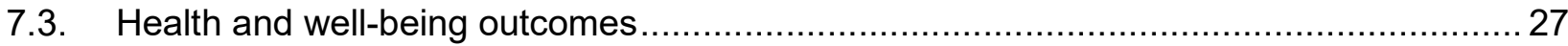

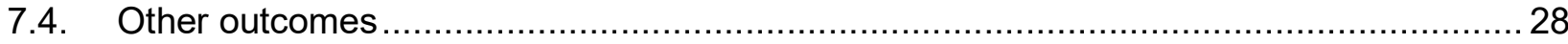

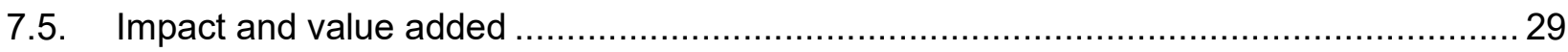

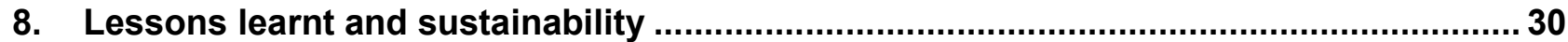

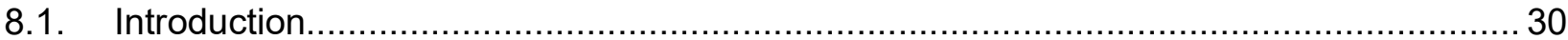

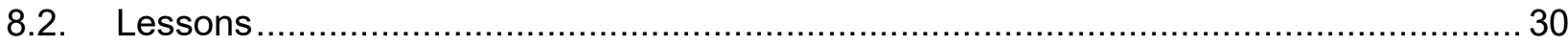

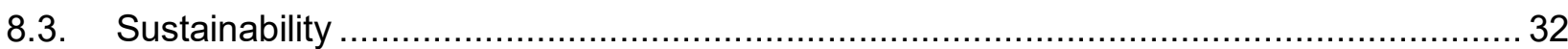




\section{Key Findings}

The Just in Time (JiT) project is a pilot designed to support those who are either on long-term health related absence from work or at risk of long-term absence in Chesterfield. The pilot provides rapid access to employment-related legal advice to clients with the overarching aim of helping them to maintain or return to employment, or, if that is not possible, to end employment in a managed way.

The project is being run by Derbyshire Law Centre (DLC) and started in June 2019 and will run to September 2021. The evaluation was carried out from November 2019 to May 2021. The overreaching objective of the evaluation was to measure the impact of the project on employment and health and well-being outcomes for clients.

\section{Some of the key findings from the evaluation include:}

- By the end of April 2021, a total of 106 people had been supported by the project.

- The project was set up to generate referrals through two key sources: GP practices and an employment support service provider (Ingeus). While the referral pathway through Ingeus was reported to work well, the GP referral pathway has been far less effective.

- Presenting needs vary by clients. Health needs include physical and mental health conditions, with the latter including anxiety, stress, and depression. Many JiT clients have pre-existing health conditions which can be exacerbated by problems faced at work.

- Most clients referred to JiT are in work and support with raising grievances is the most common form of advice sought.

- The nature and extent of support provided depends on the complexity of the case. Some issues can be dealt with a one-off phone call whereas others require more extensive casework including multiple meetings or phone calls.

- The Covid-19 pandemic has changed the nature and severity of presenting needs among clients.

- $\quad$ Support through JiT often enabled clients to return to work who might otherwise not have been able to do so.

- There is also some evidence of positive impacts on health and well-being for clients. Support helped ease worries associated with work for some, and for clients who were able to resolve their employment issues, their mental health often improved significantly as a result.

- $\quad$ Some clients making negative comments about the JiT project were those who could not be helped because of funding constraints, because there was no legal issue which could be resolved, or because they were advised that they were unlikely to achieve their desired outcome.

- $\quad$ There was a widespread consensus among stakeholders of a 'JiT effect' where project support generated additional outcomes over and above what would have happened otherwise. Most clients interviewed also expressed that had they not been referred to the JiT project, they would have been very unlikely to have sought advice or support from elsewhere.

- All stakeholders interviewed suggested a need to sustain or recommission the service in some form beyond its current lifetime. 


\section{Lesson for future support:}

There are number of lessons that can be drawn from the experience of JiT (these are discussed in more detail in Chapter 8 of this report):

- Engaging GPs: A more comprehensive and intensive engagement process needs to feature in any future programme that seeks to engage GPs. At the same time, alternative referral options could be explored, including non-clinical services such as local authority services, housing providers, Jobcentres and community organisations.

- Continuous feedback: Staff working for the main referral agency, Ingeus, clearly valued their ability to refer into JiT, but were disappointed by the lack of a feedback process on client experiences and outcomes. Any future programme should consider embedding a more robust feedback system.

- Eligibility criteria: There was uncertainty and confusion among the key referral organisation about precisely who was eligible for support. This also fed down to clients, with those not eligible for full support from the project often unsure about the reasons why they were not able to access more support. This confusion needs to be addressed to ensure appropriate referrals and confidence that individuals referred will receive the support required.

- Delivery of support: A few clients found the service to be a bit impersonal and rushed, particularly those experiencing mental health difficulties. While DLC staff recognised that mental health issues of varying degrees of severity often means spending more time with a client, these clients' experiences suggest DLC may need to build on the valuable support they are already providing to caseworkers around mental health issues.

- Promotion of the service: Quite a few clients said that they did not know what to expect from the JiT project and setting out what the service can offer more clearly and clarifying expectations would be beneficial.

- $\quad$ Strategic alignment: One stakeholder suggested that, with hindsight, JiT may have functioned better as a specialist pathway embedded within a broader strategic framework such as a wider determinants of health strategy, to reduce the risk of the project being overlooked. 


\section{Introduction}

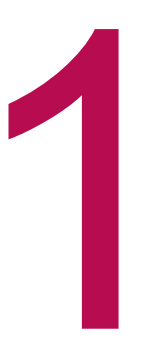

\subsection{About the project}

The Just in Time project (JiT) is a pilot designed to support those who are either on long-term health related absence from work or at risk of long-term absence in Chesterfield. The pilot provides rapid access to employment-related legal advice to clients with the overarching aim of helping them to maintain or return to employment, or, if that is not possible, to end employment in a managed way.

As well as achieving employment outcomes, the project aims to benefit clients by realising a range of other outcomes including improved health and well-being, enhanced income through earnings or other forms of financial assistance such as debt and welfare benefits advice, and support with other presenting needs such as housing. In addition, service providers may benefit through reduced pressure on services such as fewer GP visits with attendant time and cost savings.

The aims and objectives of the project have remained consistent since inception, but the Covid-19 pandemic has made them all the salient given both increasing levels of employment insecurity and negative impacts on personal well-being such as heightened stress or anxiety.

The pilot is being run by Derbyshire Law Centre (DLC) and the lead partner is Derbyshire Public Health. DLC are working together with Ingeus, who have been commissioned to provide assistance with employment issues to Improving Access to Psychological Therapies (IAPT) service users in Derbyshire, to deliver the service.

The pilot was intended to run from 1 June 2019 to 1 August 2020, however, the project has been extended twice with additional funding and will now finish in September 2021.

\subsection{About the evaluation}

The Centre for Regional Economic and Social Research (CRESR) were commissioned to undertake an independent evaluation of the JiT project. The evaluation was carried out from November 2019 to May 2021.

The overreaching objective of the evaluation was to measure the impact of JiT on employment and health and well-being outcomes for clients.

The evaluation also sought to capture lessons and identify best practice and opportunities for improvement around aspects of the programme, including service design and implementation, referral routes, delivery model, wider partnerships, governance, and sustainability. 
The evaluation involved the following key components:

- Interviews with clients. Qualitative interviews undertaken with 15 clients who had received some form of support from the JiT project.

- Interviews with project staff and wider stakeholders. Qualitative interviews undertaken with staff and stakeholders over two waves: the first during the early stages of the project and the second during the latter stages of the evaluation. In total 18 stakeholders were spoken to (this figure includes some people counted twice who engaged with both waves).

- Referral form data. Thirty of the 106 clients who had received support from the project by the end of April 2021 agreed for their referral form data to be shared with the evaluation team. The sensitivity of the issues discussed likely restricted the number providing their consent for this information to be shared.

- DLC monitoring data. Anonymised and aggregated data collected by DLC staff on referrals and clients engaged was shared with the evaluation team.

A follow-up client survey was also designed to help assess the impact of the project on employment and health outcomes for individuals. This was intended to be administered both online and via telephone by DLC staff but the impact of the Covid19 pandemic on staff capacity meant the survey was only able to be administered online. Unfortunately, the level of response to the survey was not high enough to permit the inclusion of any analysis in this report, with the exception of a few comments related to the difference support had made for clients. 


\section{Background}

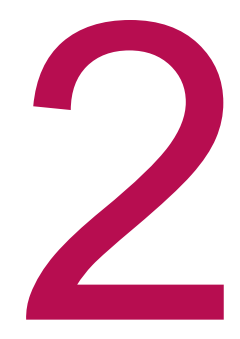

\subsection{The relationship between work, health, and legal issues}

There is a strong evidence base showing work is generally good for physical and mental health and well-beingi and the positive relationship between good quality, stable employment and good health has been recognised in a series of recent national strategies and reports. The nature of employment is also significant, and the recent Health Equity in Englandiii report emphasises the importance of good quality work $^{\text {iv }}$ for positive health outcomes. Relatedly, a number of studies have indicated a link between precarious employment and harmful effects on health and well-being ${ }^{v}$.

There is also growing evidence that social and economic problems with a legal dimension can exacerbate or create ill health and, conversely that ill-health can create legal problems ${ }^{\mathrm{vi}}$. Unmet legal needs have a strong relationship to mental health and well-being, with stress-related illnesses or other adverse consequences for mental health reported by a fifth of adults experiencing a legal problem vii. In response to these needs, partnerships between health care and legal services, such as the JiT project, have started to emerge, and integrating legal assistance with healthcare services has been shown to improve access to supportviii.

\subsection{Need for the project}

Stakeholders expressed a consensus that there was a clear need for JiT. DLC staff noted that, prior to the development of JiT, many of the clients they were seeing for legal advice had health conditions (most being mental health conditions). However, there was no specialist service at the time that took a more preventative approach to address employment-related legal issues before they had a significant negative impact on well-being. Consequently, the clients they saw tended to have entrenched health and employment issues. This suggested a need for a project that could work with health professionals to identify individuals with health and employment issues that would benefit from early legal support.

Both employers and employees often have limited understanding of employment law and rights at work which makes access to specialist support all the more important. Moreover, the stress and anxiety experienced by many facing employment issues can make it hard for employees to see or deal with their situation objectively or seek advice independently. This means it is important that health professionals have a service they can refer clients into for dedicated legal advice.

There was also a shared view that the need for JiT had increased since the start of the Covid-19 pandemic due to the new employment issues it has thrown up (see section 3.5 below). 
The project aimed to play an important preventative role in enabling clients with health issues to go back to work, where possible, by addressing employment-related legal problems that might otherwise escalate and prevent a return to the workplace. As work and health are intimately related, resolving employment issues at an early stage can, potentially, have positive knock-on effects on well-being, anxiety, stress and worry. In doing so, it prevents either employment or health issues becoming more entrenched, complex or difficult to address, thereby reducing the risk of individuals being "managed out" (DLC staff member) of the workplace through dismissal or encouragement to leave by employers. 


\section{Who has been supported by Just in Time?}

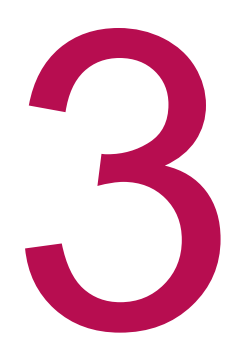

\subsection{Introduction}

This chapter examines the number of clients engaged by JiT and how this compares against targets, the characteristics of clients supported, and their presenting needs. The impact of the Covid-19 pandemic on clients is also examined.

\subsection{Clients supported}

The original aim of JiT was to support 90 people over the course of the pilot. By the end of April 2021, $122^{1}$ referrals had been made to the project and 106 people had been supported overall. JiT has therefore exceeded the target for the number of clients supported but this has only been achieved by extending the length of the project. The number of clients supported was lowest during the first half of 2020, including prior to the onset of the Covid-19 pandemic, but numbers picked up in the latter half of the year and have remained steady ever since.

Figure 1: Clients supported over time (DLC monitoring data)

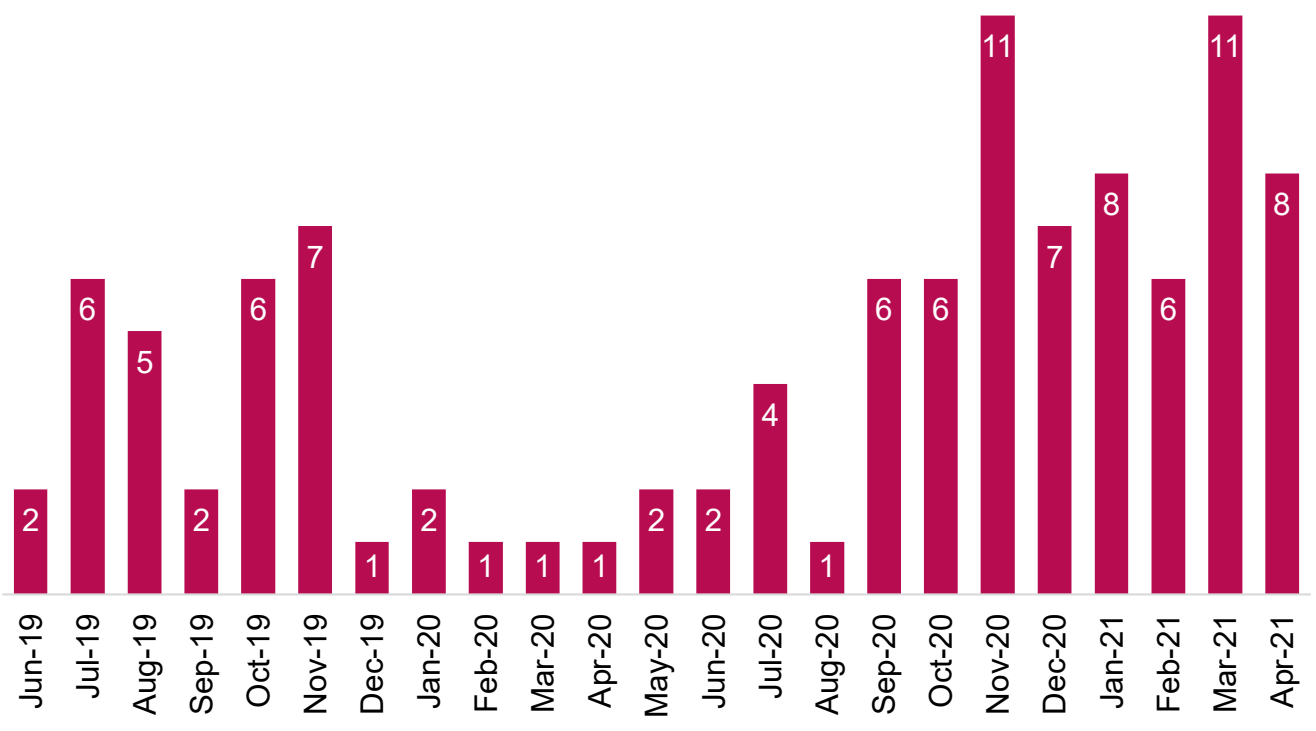

Base: 106 clients

\footnotetext{
${ }^{1}$ Of the those referred, 14 of were referred twice, with one of the 14 referred three times.
} 


\subsection{Client characteristics}

DLC staff noted that the JiT client group tend to be less marginalised than the wider population of employees with disabilities or health conditions facing employment issues at work. The latter includes, for example, groups experiencing low incomes or poor working conditions such as migrant or female workers, as well as workers with multiple or 'non' standard contracts (e.g., 'zero hours' contracts) or who work for small or medium-sized enterprises (SMEs).

The referral form data appears to support this assertion. Of the 28 clients providing information on their employment status, 27 were in work (16 of whom were on medical absence at the point of referral), and just one was unemployed. Of the 26 clients providing information on their employment contract, 25 had permanent employment contracts and 23 were working 16 hours a week or more.

DLC staff also observed that JiT clients tend to have higher levels of income than their wider client group. Again, referral data seems to support this: of the 23 clients providing information on their salary, ten had a gross annual estimated income of over $£ 25,000$ and the median estimated income for these 23 clients was $£ 19,200$. Higher levels of income among this group may reflect the referral route via the IAPT service as those with higher levels of income or education are often able to "shout loudest" (DLC staff member) to secure access to mental health support.

Referral form data, however, suggests that levels of job satisfaction among the JiT client group is low. The referral form asks clients "all things considered, how satisfied or dissatisfied are you with your present job overall, where one is 'completely dissatisfied' and seven 'completely satisfied'". Of the 21 clients providing a response, all 21 gave a score of just four or under, with 13 giving a score of just one or two.

Additionally, referral form data indicates very low levels of well-being among the JiT client group. The Office for National Statistics life satisfaction question has been used to assess levels of overall life satisfaction among JiT clients ${ }^{2}$. Of the 24 clients responding to this question, just three indicated high levels of life satisfaction (a score of seven or above). The average (mean) score for JiT clients was just 3.43, in contrast to an average (mean) score nationally of $7.51^{3}$.

GP attendance also appears to be high among the JiT cohort. Of the 22 clients providing information on visits to their GP surgery, 14 had made four or more visits in the last six months ${ }^{4}$. For many, these 'visits' will have been telephone consultations due to the shift in how primary care consultations have been taking place during the Covid-19 pandemic. Indeed, it is likely some clients who received remote consultations did not indicate these via the referral form, suggesting GP attendance may be higher than recorded in the referral data.

\footnotetext{
2 Overall, how satisfied are you with your life nowadays, where nought is 'not at all satisfied' and 10 is 'completely satisfied'?

${ }^{3}$ Source: Office for National Statistics - Annual Population Survey UK Q3 (July to Sept) 2020 estimates.

${ }^{4}$ For a national comparison: Primary care consultations per person fell from an average of 4.1 before mid-March in 2020 to 3 consultations per person per year (around a 30\% reduction) the week after the introduction of lockdown at the end of March. Rates were still at that level in the most recent data (end of June). https://www.health.org.uk/news-and-comment/charts-and-infographics/use-of-primary-care-during-the-covid-19pandemic
} 
The project is supporting clients across a range of ages (see Figure 2 below), although a smaller proportion of those aged 18-24 and 65 and over have received support (that fewer over 65s have been engaged is unsurprising given many will no longer be in employment).

Figure 2: Age of clients supported (DLC monitoring data)

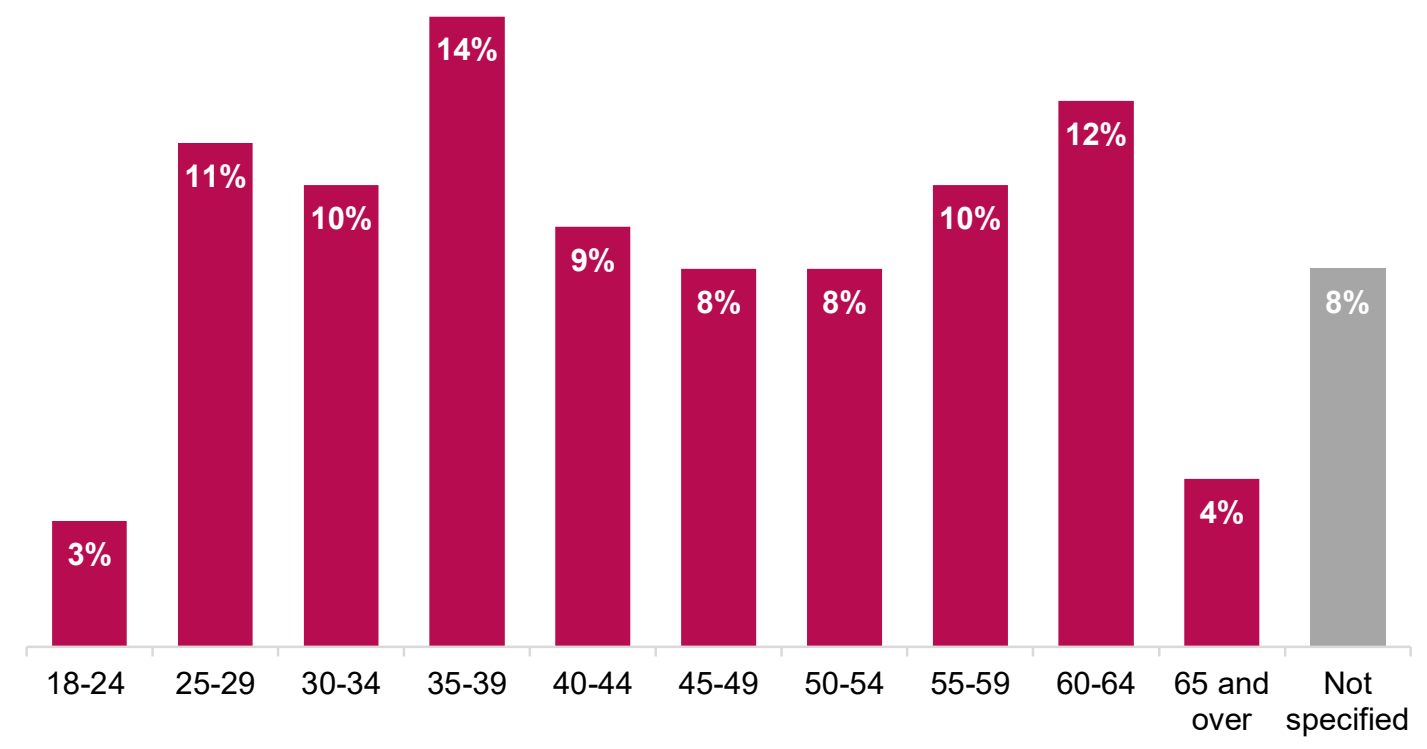

Base: 106 clients

DLC monitoring data also indicates that just over one quarter of those receiving support by the end of April 2021 considered themselves to have a disability. For the remaining clients, disability status is unknown ${ }^{5}$, suggesting this figure is likely to be higher.

Of the 36 clients featuring in the monitoring data whose gender was indicated, 19 were female and 17 were male. Ethnicity is known for 19 clients, of whom 15 were White British/English.

\subsection{Presenting needs of clients}

DLC staff indicated most clients referred to JiT are in work and that support with raising grievances is the most common form of advice sought. Referral form data supports this, with 17 out of 28 clients indicating issues with grievances (see Figure 3 below). A greater number of clients also indicated problems with stress at work.

Presenting needs and their intensity also varies by client. While ten out of the 28 clients with available referral data indicated one or two presenting legal issues, 18 indicated three or more issues, with nine indicating four or more.

\footnotetext{
5 There is a lack of some information and since October 2020 DLC have taken significant steps to increase data capture. Prior to that data would often be based on information from the referral form which was not always completed in full.
} 
Figure 3: Presenting legal issues (referral form data)

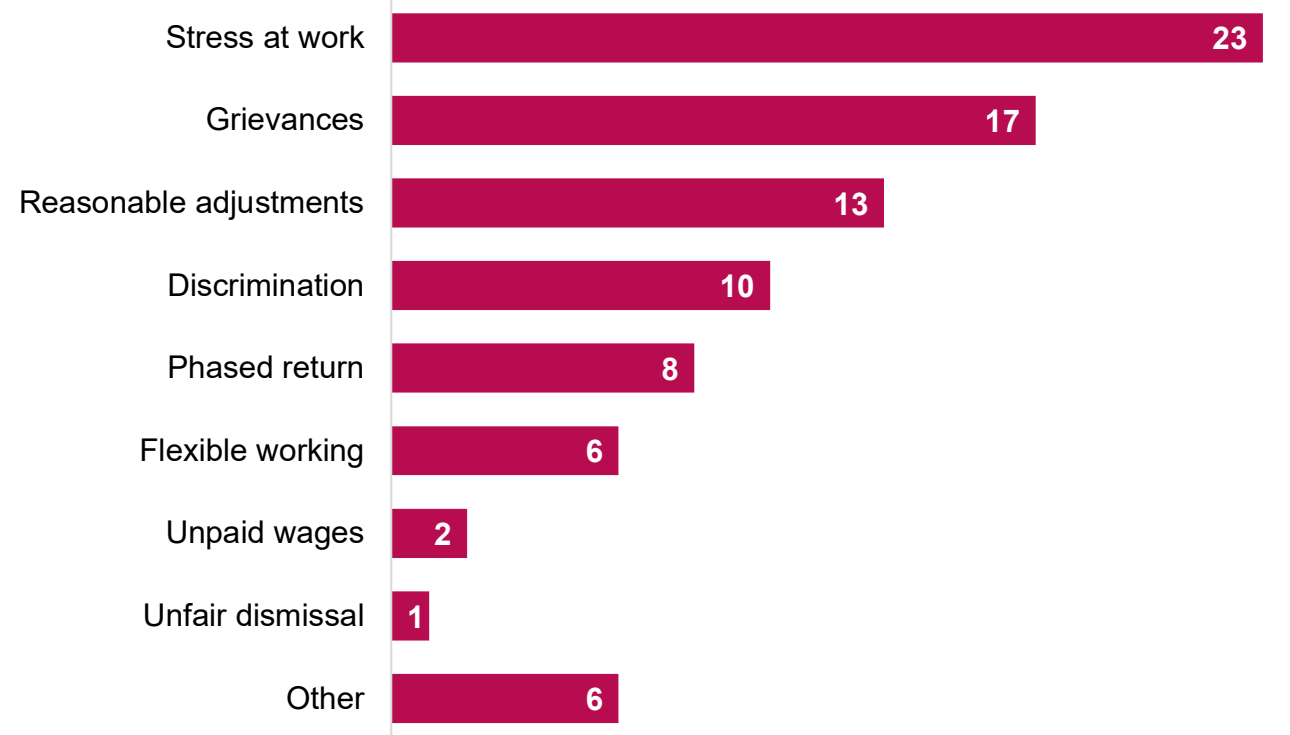

Base: 28 clients

In terms of employment needs, DLC staff indicated some cases are relatively straightforward such as where clients need one-off advice on grievance procedures or entitlement to holiday or redundancy pay. Other cases require more extensive and complex casework such as where there has been failure to implement adjustments, unfair dismissal, bullying or discrimination, or there is a need to see or request evidence (contracts, letter from employers etc). Clients on medical leave also seek advice on whether they should return to work or leave their job permanently. While employers do not always understand or adhere to employment rights, some clients also need support from the JiT team to recognise that their employer is acting reasonably and/or lawfully (e.g., by requesting a medical report).

The clients interviewed as part of the evaluation were seeking advice and support for a variety of employment issues such as discrimination at work including bullying, disciplinary action, contractual issues, dismissal, issues around sickness rights at work, entitlement to sick pay and redundancy. Clients typically wanted to establish what their employment and/or legal rights were in relation to their specific work situation:

"I just wanted some clarity from somebody legal as to where I stood, what I could do, could I walk away". (JiT client)

"I was going through a disciplinary at work and I just wanted to get some advice around the best way to resolve the situation and someone to look at all the information they had and say, this course of action would be better or that course of action would be better". (JiT client)

"The issue I had...was regarding discrimination so I started a process during being furloughed to kind of pre-empt taking [my employer] to court, basically because their behaviour was just appalling from the start”. (JiT client)

"I've gone through an investigation and disciplinary, I'm not there anymore but I wanted some advice on that". (JiT client) 
DLC staff indicated health needs experienced by clients include physical and mental health conditions, with the latter including anxiety, stress and depression, as well as wider problems such as debt caused by drops in income while on statutory sick pay or when moving onto welfare benefits. Mental health conditions usually predate, but can also be exacerbated by, workplace issues: "If you are not feeling comfortable, listened to and supported, it really impacts on mental health" (DLC staff member).

Most of the clients interviewed were signed off from work on medical leave by their GP when they were referred to JiT. Being signed off from work was typically the result of work-related stress or anxiety and being away from the workplace helped to relieve this. Overall, the most typical health reasons that were talked about were anxiety, stress, depression, and general mental health issues. One client was signed off because of Covid-19 and another had physical health issues in addition to mental health problems.

Many had pre-existing issues that were compounded by their situation at work, and it was typically the case that a particular incident at work had caused further stress or anxiety leading to them being signed off:

"I'd been signed off work due to stress and depression and what had compounded that was the fact that I believed at the time, that I was being forced into a position where I would leave the company". (JiT client)

"I'd spoken to my doctor about some anxiety and depression issues, partly related to work issues... [work] was almost like a trigger". (JiT client)

"Lots of things had been building up and...speaking with the therapist I discovered things like I've got 'perfectionist syndrome' which has meant that... I never get any enjoyment out of things...I feel like they're failures. It may part of the reason for why l've had issues at work because...I get frustrated. But [the disciplinary situation] at work triggered off that l've not been happy for a long time...". (JiT client)

For some of those interviewed, the support provided by DLC was part of a package of help they were receiving and was complemented by other support such as counselling, Cognitive Behavioural Therapy, and other employment support, although the specialist legal advice being provided by DLC was not being duplicated elsewhere.

\subsection{Impact of the Covid-19 pandemic}

The DLC team reported that the onset of the pandemic in March 2020 led to a flurry of related cases around issues such as selection processes for furloughing; fear of returning to work if medically vulnerable; concerns over whether workplaces were Covid-safe; and selection or payments for redundancy.

The Covid-19 pandemic has changed the nature and severity of presenting needs among clients. Impacts include increasing employment insecurity, deteriorating mental health, and fewer opportunities for social interactions, routines or activities that support well-being: "[They are] sitting in a living room with more time to think" (DLC staff member). It has also introduced a new set of employment issues such as concerns that employers are not putting in place adequate protections to make workplaces Covid-secure or are pressuring medically vulnerable employees to return to work.

Stakeholders felt the pandemic will continue to shape the challenges faced by clients in the longer-term due to the potential impacts of long Covid, the impact on 
unemployment when furloughing ends, and the use of remote working which may present both opportunities and challenges.

\section{Client interviews also suggest the pandemic has exacerbated work pressures for some or made looking for work more challenging.}

One client discussed the challenge of looking for an alternative job during the pandemic. They had returned to work following maternity leave and been informed by their employer that they could not accommodate a change to their hours. They had been unhappy for some time in their job and had also experienced postnatal depression. In the end, they felt that in terms of their mental health, they had no option other than to hand in their notice:

"I was sort of already kind of looking for a job but obviously with Covid and everything it made things a lot more harder so it would have been easier to go back there for the time being". (JiT client)

Another client who had been signed off sick due to depression found the furlough process had complicated their return to work:

"Our company deliver beer and obviously with all the pubs and that being shut, we weren't sure when we were getting back to work because a lot of people had been on furlough, a lot of people hadn't, and we just needed Derbyshire Law to push them and try and get me back in to work really". (JiT client)

For one client who worked in a support capacity, the impact of the pandemic had contributed to their stress and depression, which led to them being signed off work:

"In retrospect [the pandemic] didn't help. It wasn't everything. It wasn't all about it. But I think I was taking on board a lot of the stresses and strains that a lot of volunteers and people that work for us were feeling... and you feel helpless in some respects...you can't help them all the time..... (JiT client)

Another client working in healthcare discussed how the pandemic had created a lot of additional work, with lots of changes to processes and procedures, and that they felt "very uncomfortable with it". This situation contributed to them being signed off sick from work with anxiety and depression.

There was one interviewee, however, who had been suffering with anxiety, depression, and stress for two years, who found the pandemic had helped relieve their stress at work:

"In a way, the pandemic has been...helpful because [it meant] I could work from home, so it took out the stress of the commute. That was a couple of hours a day. It meant less emphasis on me being interactive with people throughout the day because there were days when I didn't necessarily want to be interactive with people so that's easier sat at home in your home office than being sat in an open plan office. So, to a degree, the whole lockdown thing has shielded me from the stresses I was encountering on a regular basis". (JiT client) 


\section{How has Just in Time been delivered?}

\subsection{Introduction}

This chapter examines the JiT delivery model, namely referral routes into the project, response times and the nature of support provided to clients.

\subsection{Referrals}

$\mathrm{JiT}$ was set up to generate referrals through two key sources: GP practices and an employment support service provider (Ingeus). The GP referral pathway was designed to refer patients that have a health issue that is related to a problem in the workplace. The Ingeus referral pathway routes individuals through specialist mental health and employment support into JiT. Ingeus receive referrals from the IAPT service where the IAPT team deem health issues to be related to work. Ingeus subsequently refer on to JiT where they feel a client would benefit from legal advice to address their employment issue. Individuals may also self-refer such as those making contact after seeing a leaflet in a GP practice or at an IAPT appointment.

The referral pathway through Ingeus was reported to work well by DLC staff with only temporary disruption to referrals when Ingeus and DLC switched to remote working during the first lockdown. One reason it functioned well is that there was a clear pathway of support between a clinical service (IAPT) to an employment support service (Ingeus) where staff are trained to spot employment issues that require legal advice. One external stakeholder suggested this works better than direct referrals by clinicians who have less immersion in employment issues.

DLC monitoring data indicates, of the 122 referrals made to the project by the end of April 2021, 118 were referrals from an Ingeus advisor and four were selfreferrals made by clients following Ingeus advice.

By contrast, the GP referral pathway has been far less effective as it proved challenging to engage practices, particularly once the Covid-19 pandemic broke out. DLC made contact with a number of GP practices in the early phases of the project. Despite initial "good signs" (Derbyshire Public Health staff member) from the Primary Care Network and some individual practices, referrals proved very slow and "fell completely flat" (DLC staff member) once the Covid-19 pandemic broke out in March 2020. 
A number of reasons were volunteered for the challenges faced in establishing the GP referral pathway:

- Insufficient GP engagement activity: the project was launched as soon as funding from Derbyshire Public Health was secured and the IAPT service and Ingeus were on board. While important to sustain this momentum, DLC staff reflected that, with hindsight, the launch could have been delayed to allow for more time for intensive engagement work with practices.

- Restructuring of the primary care system: the project launched at a time when the Primary Care Network (PCN) of 12 practices was being set up in Chesterfield. This major restructuring of the primary care system made it difficult to establish clear referral pathways at a time when "internal politics were still setting down" (Derbyshire Public Health staff member).

- Variable commitment across and within practices: there was often support from individual practice managers who were "very keen" (DLC staff member), but this did not translate into buy-in from GPs. One explanation was that GPs may not have had the time during consultations or sufficient awareness of JiT to make referrals.

- The lack of a physical presence in GP practices: JiT did not have the resource to physically embed themselves in, and operate from, GP practices in the way that services like Citizens Advice do which may have limited awareness.

- Lack of referrals from social prescribing services: anticipated referrals from the social prescribing service operating out of GP practices did not materialise, both because use of the service was limited, and social prescribing staff did not fully promote JiT.

- Covid-19: the pandemic saw the limited number of referrals dry up completely as patients stopped attending surgeries during the first lockdown and GP practices focussed on preventing transmission.

The challenges in generating GP referrals provide key points of learning for any future commissioning (see Chapter 8). However, it is also important to recognise that JiT was victim to "poor timing" (Derbyshire Public Health staff member) in terms of failing to secure full commitment from the new PCN before the pandemic hit. Moreover, as one external stakeholder noted, the lack of initial referrals becomes self-perpetuating as GPs do not receive feedback on positive patient experiences that might have encouraged further referrals.

\subsection{Response times}

A key feature of $\mathrm{JiT}$ is the ability to provide rapid, expert legal advice to those referred to the project. Chesterfield residents eligible for full support from the project will receive a response within 24 hours. DLC's standard service involves a receptionist taking a client's details and a call-back from a gateway assessor before referral to a specialist. This can take two or three days, or longer at very busy periods. The JiT project bypasses the gateway assessment. Client details are emailed to a dedicated email address which is constantly monitored. Once received, referrals are immediately allocated to a rapid referral slot for a specialist call-back. When it was decided to extend the catchment of the JiT project to the whole of Derbyshire, all JiT referrals were given a rapid referral call-back slot if one was available, with first priority being given to Chesterfield residents. Further assistance, where required, was then provided by the standard specialist casework service. What could then be provided varied, depending on funding available. Funding criteria include a client's place of residence 
and economic status, as well as the complexity and merit of their legal issues (see Chapter 5 for discussion on eligibility for support).

The majority of clients interviewed were contacted quickly by the JiT service, on the same day or within a day or two of referral.

\subsection{Support provided}

The nature and extent of support provided by JiT depends on the complexity of the case. Some issues can be dealt with a one-off phone call whereas others require more extensive casework including multiple meetings or phone calls. As Figure 4 below, illustrates, all clients engaged by the end of April 2021 had received advice via a specialist telephone appointment and 15 per cent of clients had had casework undertaken by DLC on their behalf.

Prior to the Covid-19 pandemic individuals with more complex cases would be offered a face-to-face meeting at DLC or an outreach venue closer to their home. Since the pandemic all contact is made remotely by phone. If further support is required after the initial appointment, this might include advice on returning to work; requesting reasonable adjustments, for instance to hours or other working practices; requesting an occupational health report; help with raising a grievance; advice on legal action that can be taken; negotiation on settlement out of court; assistance and representation with an Employment Tribunal claim.

Figure 4: Type of support provided

Specialist appointment - via telephone

Received follow-up advice in writing (e-mail or letter)

Casework undertaken by Derbyshire Law Centre on client's behalf

Specialist appointment - face-to-face
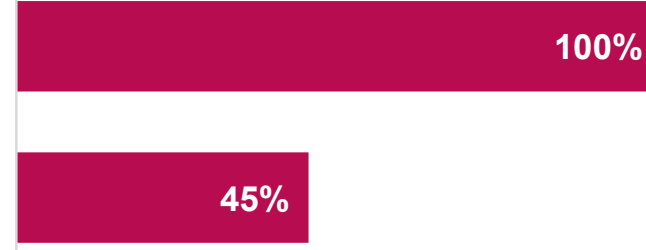

$15 \%$

Base: 106 clients

Until the autumn of 2020, funding for employment cases at DLC meant there was a limit of six hours of casework unless further funding could be found, for instance when a client with a discrimination case was eligible for legal aid. Since last autumn, funding has been available which has removed the six-hour limit where the legal merits and complexity of the case, and the vulnerability of the client permit it.

DLC take a holistic approach to clients and provide internal referrals for debt, housing, and immigration issues. External referrals are made when DLC cannot advise, for example for advice on welfare benefits or personal injury claims relating to employment.

Not all individuals referred or who make a self-referral will necessarily take up support offered. Mental health conditions such as stress and anxiety, for example, deter some 
individuals from accepting support that they fear may lead to tension and conflict with employers or exacerbate health issues.

\section{Client interviews}

None of the 15 clients interviewed had any casework completed on their behalf, nor did DLC have any direct contact with people's employers. Clients typically had a phone call and/or email exchange with a member of the JiT team to discuss the specifics around their issue. For some clients support constituted one phone call, whilst others received a combination of phone calls, letters and emails.

Other examples of support provided included DLC writing letters on behalf of clients to send to their employer (typically the HR department) and checking an employer's occupational health report to ensure everything was in order. Advice was also given to one client on how they should set up a meeting with their HR department and manager and how to best approach this meeting.

Some clients mentioned that they were signposted by DLC to support elsewhere, often Citizens Advice and ACAS (the Advisory, Conciliation and Arbitration Service), but they did not typically take this help up, or in some cases had already sought help from these organisations prior to getting in touch with DLC. 


\section{Effectiveness of support}

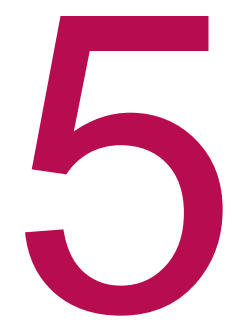

\subsection{Introduction}

This chapter reviews stakeholder perceptions of the effectiveness of support provided by the JiT project. Client experiences of support are also examined, including expectations about support and perceptions of the quality of advice received. Issues associated with eligibility, raised by both stakeholders and clients, is also considered.

\subsection{Stakeholder perceptions of effectiveness}

The main referral agency, Ingeus, reported that clients highly value the support provided by the JiT team who are considered "“really helpful" (Ingeus staff member). It is faster and more responsive than the Citizens Advice service which clients can be reluctant to contact due to challenges in getting through by phone. DLC can sometimes sort an issue out within a couple of weeks where other services - especially Citizens Advice - can take months. Stakeholders noted that speed of response is crucial as health conditions can decline while waiting for support. The fact support is free is also a "massive key thing" (Ingeus staff member) for clients given that a lot of employment law is out of scope for legal aid.

\section{Eligibility for support}

There was, however, some uncertainty and confusion among the key referral organisation about precisely who was eligible for support. Stakeholders noted that those living outside Chesterfield or who had access to legal support through their union were not technically eligible. However, there were mixed experiences about the extent to which these eligibility criteria had been adhered to. One interviewee suggested a number of clients had not been able to access JiT as they lived outside the geographical boundaries for referrals or were in a trade union. They noted the irony of the geographical criteria which excluded some of those most in need in inner urban areas of Derby. By contrast, another colleague suggested that "no one gets turned away" (Ingeus staff member) for being in a union but that clients have been for living outside Chesterfield.

Either way, all stakeholders in the referral organisation noted the importance of access to good quality specialist legal advice. This meant union membership should not be a criterion for exclusion as support from union representatives was not always "good enough" (Ingeus staff member) as it depended on the interest, approachability and competence of representatives.

The lack of clarity about eligibility criteria may be explained by the degree of flexibility the DLC team exercise in taking on cases. 
The team report that decisions about the level of support to provide varies according to place of residence, access to legal advice through trade unions, likelihood of case succeeding, the potential value of claims, and perceived vulnerability of potential clients. While access to legal advice through a union technically precludes support, this may be waived for more vulnerable clients, particularly if union support is not considered effective or appropriate (e.g., where the trade union representative is a colleague). Alternatively, DLC caseworkers may decide not to take on cases if deemed unlikely to succeed or to be of low value ${ }^{6}$.

\subsection{Client experiences of support}

\section{Expectations}

It was clear from the interviews that most clients did not know what to expect from the JiT project or were unsure about what help and advice would be available to them. Most had been advised by Ingeus that the JiT project would be able to offer some help and a couple of clients mentioned receiving support from Insight counselling and being told that they might benefit from clarifying their rights at work via the JiT project.

In some cases, clients' expectations of the service were exceeded. One client explained that they would "not easily" have found the same information elsewhere about what the procedure for them going back to work should be ('return to work under protest'). They stated that the project has been a "life saver":

"I do believe the projects a life saver for me and its certainly helped my stress levels go down because I knew I had the backing of the law then and what I thought I was entitled to, was correct...I don't think l'd have found anything directly and certainly not the state I was in. I don't think I'd have got through trying to google everything and try and work it all out myself". (JiT client)

Another client explained that the advice they received from the JiT project exceeded their expectations from "start to finish", saying "it was much better that I expected it to be".

A number of clients also stated they would recommend the JiT project to others in a similar situation. One client explained they would recommend the project because there are times when people will need the sort of advice provided by JiT, particularly those who cannot afford legal advice or who work for SMEs etc., and it is reassuring to have your rights confirmed:

"Even just half an hour speaking to a legal professional could work wonders for somebody and really help somebody". (JiT client)

\section{Quality of advice}

The interviews also reveal, however, that clients' perceptions of the quality of advice received from DLC varied. For some clients, the advice received was seen as very helpful, enabling them to resolve their employment issue, and they were very happy about the outcome:

\footnotetext{
${ }^{6}$ Legal aid is only available in discrimination cases and not other areas of employment law which also limits the level of risk the DLC can take on.
} 
"I just needed somebody that knows the ins and outs of it and my situation and the knowledge and everything to write a decent letter and get it sent and get me back as soon as possible and it worked". (JiT client)

"I don't know where I would have stood with going back to work or how work would be with me, so it definitely helped". (JiT client)

"In the second or third email, [JiT] included a template letter and they said if HR start being funny, you send this template off and print the letter off explaining what my rights were...luckily l've not had to use it". (JiT client)

The advice that clients received often provided them with much needed "clarity "about their legal position and possible options, and as one client described, helped "guide me in the right direction".

However, some of the clients interviewed felt that they were provided with very little advice or support. For example, one client explained:

" $[D L C]$ rang me in the first instance. However, by that time l'd already ran over the time for appealing it with the final decision at work and I explained that, and I was...forced to give my notice in. It was no fault of Derbyshire Law, my previous work were just being awkward with me and quite intimidating". (JiT client)

This client had "limited expectations of the project" but stressed that it would have been good to have found out about JIT sooner:

"...on my part, I probably should have seen if I could access the Just in Time project sooner, then I might have been a little bit more critical and been in a better mind frame to take the appeal further but I think it was just bad timing...". (JiT client)

It was apparent that some clients did not have a positive experience of the JiT project because their circumstances and/or the legal constraints associated with their case meant they were unable to achieve the outcome they hoped for. This led to disappointment and in some cases further distress:

"The law firm could not help me due to the constraints in the way the law works in terms of three months less a day and they couldn't find any leverage and ways in to taking them to court through any other complications in my furlough and so in conclusion, unfortunately it just contributed towards a bit of a downfall in my psychological health". (JiT client)

"The advice and information was all correct I'm sure...but [what] I needed was someone to look at my specific case and give specific advice on it and I didn't get that so I didn't find that it helped that much...there was nothing else they would do or could do, It was a case of having the conversation and giving me some information and that was it, I then didn't expect to have any more contact with them based on that initial conversation and I went back to speak with the employment people [Ingeus] that I was originally put in touch with on the counsellor side". (JiT client)

In one instance, a client had expected to receive further advice from DLC but was still waiting to resume communications:

"The person I spoke to said [my case] was quite a unique thing and he have to go away and speak to a colleague about it, but I never heard anything back and that's where it all sits at the moment". (JiT client) 


\section{Eligibility for support}

The uncertainty stakeholders felt over eligibility criteria also fed down to clients. In our interviewee sample, even though all clients received at least some form of support from JiT, quite a few seemingly did not qualify for full support from the project and some clients were unsure about the reasons why they were not eligible or able to access support. For example:

“They wasn't very helpful to be honest. They just said because I wasn't under mental health and because I hadn't actually been dismissed, because of how much I earn they wasn't able to help me and referred me back to either a solicitor or joining the union". (JiT client)

Other clients were clearer on why they could not access more support, although this still led to disappointment. For example, one client stated:

"I was sort of expecting to get more support [from DLC] so I was a little disappointed when I found out that she would be able to do anymore...but I understood the reason for that so that was fine... she recommended that I spoke to ACAS regarding [my issue] and Citizens Advice which I couldn't get hold of anybody at Citizens Advice at all but I have spoken to ACAS on a few occasions but because I wasn't with a Union either...and l've signed up with a Union since but because that was...after the whole process started they weren't able to assist me so l've had to sort of deal with everything myself...". (JiT client)

\section{Delivery of advice}

There was a sense from a few clients that the way the service was delivered at times was a bit impersonal and rushed:

"If you want to give this service, deliver it a little better. It is a good service that will help lot and lots of people there is no doubt about that but get them to be a bit more courteous and polite and deliver it better". (JiT client)

"I felt as though I was on a time limit and they hadn't got time to talk to me and it was more of an inconvenience, cos at that point I was desperate". (JiT client)

One client described the advice they received over the phone as "clinical", "not tactful" and "quite blunt" and did not feel that the person they spoke to had taken their mental health in to consideration:

"...when I then started to clam up and have a panic attack, my wife had to take over and she sort of explained...and then I think he realised and started to become a bit more amenable to the situation...l don't know what kind of information gets shared...but I do think if people have anxiety or depression...it could be helpful for Derbyshire Law to know so that they can bear that in mind when they call people". (JiT client)

Another client explained that their mental health difficulties often made it difficult for them to reach out for support and this was compounded by a lack of contact and communication for DLC. They felt it would have been beneficial to have had face-toface contact and communication with the project as this would have enabled them to engage more meaningfully/effectively. They did, however, acknowledge that that this could not be helped because of Covid-19 restrictions. 


\section{Outcomes achieved: stakeholder assessment}

\subsection{Introduction}

This chapter reviews the outcomes of JiT support reported by stakeholders. It considers the extent of benefits experienced by clients in terms of resolution of legal issues as well as outcomes around employment or health and well-being. It then reflects on the extent to which the project has shaped employer practices and workplace cultures, as well as the benefits experienced by partner organisations. The chapter moves on to look at broader factors that explain successes or challenges in achieving outcomes. It concludes by examining the impact of JiT in terms of the extent to which outcomes have been achieved over and above what might have happened if the project had not been in place.

\subsection{Client outcomes}

\section{Legal}

DLC project staff reported that they had been successful in resolving legal issues such as securing reasonable adjustments, pay during a notice period, or compensation if unfairly dismissed. There was also a view that legal advice can give clients the confidence, knowledge, and motivation to insist on their rights or seek redress: "They get a bit more agency" (DLC staff member).

DLC staff also noted, however, that dealing with employment issues related to the pandemic had been challenging legally as there was no existing body of law to draw on other than elements of health and safety legislation. This sometimes proved difficult when supporting clients as, for example, there is no right to be furloughed which remains discretionary.

A further effect of the pandemic is the "huge backlog" (DLC staff member) in the employment tribunal with cases taking at least 18 months to be heard. This can have "really bad" (DLC staff member) impacts on mental health which is adversely affected by the length of time waiting for decisions. One implication is that DLC caseworkers have increasingly sought to encourage clients to engage in "preventative" action where they seek to resolve issues with employers first rather than later "contentious" action that ends up in the employment tribunal. One advantage of JiT funding highlighted by DLC staff is that it enables preventative work which other funding sources preclude as they tend to only support contentious action once cases have become more entrenched. 


\section{Employment}

A positive employment outcome for $\mathrm{JiT}$ clients usually means a sustained return to an existing workplace. However, in some cases where clients felt unable to stay in their current job due to employment or health issues, a positive outcome comprised advice and guidance to leave employment on the best possible terms.

DLC staff reported that support through JiT often enabled clients to return to work who might otherwise not have been able to do so. This claim around impact is corroborated by stakeholders in the main referral agency Ingeus who suggested JiT support could have a "massive effect" (Ingeus staff member) in supporting clients to return to jobs. Examples included:

- Example 1: A client who experienced bullying and was on medical leave put in a formal complaint in but was worried about the repercussions when they returned to their job. Speaking to JiT staff gave them the confidence and knowledge of their rights they needed to go back into work. This "really beneficial" (Ingeus staff member) return to their job may not have happened otherwise as Ingeus staff did not have the necessary legal knowledge while the wait for support from other services providing legal advice would have been too long.

- Example 2: One client who worked in a school and was classed as extremely vulnerable took medical leave due to stress as they felt their employer was not following Covid-safe guidelines. DLC staff advised the client on the responsibilities of their employer, giving them the confidence and knowledge to request changes and return to work. This may not have happened without DLC support as employees are reluctant to challenge their employer in the middle of a pandemic because of the perceived insecurity of jobs.

A further benefit of returning to work suggested by Ingeus was enhanced financial well-being as clients begin earning after periods on statutory sick pay or welfare benefits.

DLC caseworkers attributed a number of factors to positive employment outcomes including:

- Helping distressed or anxious clients see their employment situation objectively is often a prerequisite for developing pragmatic solutions. Crucial here is having the time to support clients to "offload" initially about concerns before discussing practical resolutions.

- Giving clients legal advice provides the "confidence" and "peace of mind" to negotiate rights and adjustments at work and challenge discrimination.

Not all attempts to support clients to return to work were successful however and, in some instances, this was partly due to employee inflexibility. In one case, for example, a client who wanted to return to the workplace rather than return to home was unable to do so because the employer was following Covid-19 guidelines. This indicates that employee attitudes as well as employer practices can shape employment outcomes.

\section{Health and well-being}

Many JiT clients have pre-existing health conditions which can be exacerbated by problems faced at work. Mental health in particular can be negatively affected when employees feel powerless to deal with unfair treatment or anxious that taking action against employers could threaten job and, by extension, financial security. As one stakeholder noted, employees may experience these situations as a "threat" which 
makes them "extremely vulnerable" and have potentially significant "emotional and financial impacts" (Ingeus staff member). For this reason JiT has the potential to impact positively on health and well-being where support addresses issues at work.

Both DLC caseworkers and the main referral partner Ingeus suggested support impacted positively on clients in three main ways. First, the empathic approach of caseworkers in listening to concerns had positive impacts on well-being regardless of legal advice as it provided emotional support and reassurance that was sometimes lacking from employers:

"By the end of the conversation they are thanking you: 'I feel so much better'". (DLC staff member)

"The client was really grateful I was listening...grateful I cared". (DLC staff member)

"[Offering jJiT support] takes the worry away from clients by taking responsibility for their issue...it's a massive relief, you can't put it into words. You can see the physical signs of relief, literally a deep sigh. It changes their appearance and everything". (Ingeus staff member)

It should be noted, however, that there was a sense from a few clients interviewed that the way the service was delivered was occasionally a bit impersonal and rushed (see section 5.3 of this report).

Second, legal advice can provide a sense of empowerment and restore agency to individuals by giving them the confidence and knowledge to take actions to address challenges at work:

"People feel they have justice and go from being powerless to winning. They feel more in control ... successful and confident". (DLC staff member)

Third, a return to work itself can enhance well-being. Caseworkers acknowledged that there was no formal measure of enhanced health and well-being to substantiate this but suggested positive employment outcomes made clients "happier".

The health and well-being benefits experienced by some clients led one stakeholder in a referral agency to suggest that support from JiT can actually aid recovery from some health conditions.

\subsection{Employer practices and workplace cultures}

Interviewees were asked whether JiT interventions had led to changes in employer practices and workplace cultures by promoting greater awareness and sensitivity around supporting employees with health issues. The aim was to assess the extent which the programme was generating wider and more sustained culture or system changes beyond the benefits to individuals supported.

Interviewees were cautious, however, about suggesting that JiT had positive impacts on employer practices or processes. While interventions from JiT undoubtedly led employers to make changes such as reasonable adjustments (e.g. around breaks or set up of workstations), it was difficult to identify lasting change in workplace cultures more broadly:

"The thing is you don't know how they will be treated. It's hard to change the culture of a workplace...do we change employers practices? It's ambitious to say we can do that". (DLC staff member) 
Another interviewee in an external partner agency concurred that it was difficult to say whether the project had achieved changes in employer practices. Nevertheless, they suggested with "a bit more traction and direct engagement" (Derbyshire Public Health staff member) that the project could be successful in changing employer practices, processes and protocols.

\subsection{Benefits for partners}

Partner agencies reflected on the value of involvement with JiT in terms of supporting their operational or strategic priorities.

Staff working for the main referral agency, Ingeus, clearly valued their ability to refer into JiT with one interviewee suggesting they "couldn't fault it' (Ingeus staff member). They noted that it enhanced their employment support offer by giving clients access to rapid, expert legal advice that Ingeus would otherwise not be able to provide in house. It clearly gave confidence to employment advisers interviewed that legal issues relating to employment could be addressed. One external partner reflected that the added value of JiT to Ingeus' offer was one of the most effective parts of the project. Indeed, this perception of added value underpinned the decision to extend funding by six months through the Chesterfield Wellbeing Fund administered through the Public Health team.

However, employment advisers noted issues with a lack of communication or feedback following referrals:

"I have difficulties with communication. If I could contact DLC [about clients] that would be a massive step". (Ingeus staff member)

One of the main funders of the project, Derbyshire Public Health, also observed that JiT aligns "front and centre" with their core priority of reducing health inequalities. This alignment had become all the more salient as health inequalities have widened during the Covid-19 pandemic.

One external partner also noted that, anecdotally, local partners including Citizens Advice and the Derbyshire Unemployed Workers Centre reported benefitting from JiT as project support around employment issues had reduced the complexity of issues individuals were presenting with.

\subsection{Success factors}

Stakeholders identified a number of broader factors contributing to positive change:

- Dedicated funding provided the time and space needed to support clients with health and employment issues through casework that can be "time consuming and difficult" (DLC staff member). As one caseworker reflected, mental health conditions mean JiT cases are more complex than other DLC work and require "a lot of time and effort in to managing clients, managing their expectations, maybe helping to shift perspective if someone is stuck in a rut" (DLC staff member).

- Early intervention before cases become complex and entrenched was "the absolute key" (DLC staff member) to successful outcomes as it increases the chance of a return to work while minimising negative health impacts. Caseworkers noted that, unlike some other funding sources, JiT funding enabled them to intervene in cases at "an earlier point....where [grievances] are preventable and [legal support] is more likely to be successful" (DLC staff member). Timely resolution of employment issues can also prevent wider problems e.g., around debt and housing emerging. 
- The personal skills of caseworker are important as clients' mental health can be fragile, requiring empathic support that extends beyond the presenting legal issue. The ability to listen, empathise and build trust and rapport are essential: "YYou have to let] people speak and be sympathetic... This makes people feel they can open up and be listened to". Again, while many clients were happy with the support they received, it should be noted that some of the clients interviewed found the support less empathetic (see section 5.3 of this report).

- The ability of the referral agency to encourage take up of legal support that clients may otherwise be reluctant to access independently, especially if experiencing anxiety, stress and depression. Employment advisers reported they can reassure clients about the potential value of support, give positive examples of previous clients' experiences, and help them with practicalities such as filling in forms.

- The qualities of the project manager who brings "empathy, understanding, professionalism...and passion" (Ingeus staff member) to the project.

\subsection{Challenges}

A number of challenges to delivering the project were identified by caseworkers:

- Mental health issues of varying degrees of severity sometimes made it harder to support clients. DLC addressed this through a dual approach of using in-house mental health champions and training staff around mental health and suicide awareness. Until the pandemic, home visits could also be provided if the client preferred. However, poor mental health sometimes meant that clients did not want DLC to take their case forward.

- The Covid-19 pandemic increased anxieties to such an extent in some cases that clients refused to return to work, even if employers took reasonable steps to make workplaces Covid-secure. In these cases, DLC were often unable to find a solution.

- Cuts under 'austerity' have reduced access to services including legal advice. One external partner suggested JiT can mitigate some of these impacts through early support which reduces the need for 'downstream' interventions but considered the project too small to achieve this at scale.

\subsection{Impact and value added}

Interviewees offered a number of reflections on the impact of JiT in terms of the extent to which it achieved outcomes that would not otherwise have occurred. There was a widespread consensus of a 'JiT effect' where project support generated additional outcomes over and above what would have happened otherwise. This additionality was explained by reference to a number of factors:

- $\quad$ The dearth of alternative free legal advice on employment issue meant JiT was not duplicating other support. ACAS and Citizens Advice can provide limited advice on work-related issues but not specialist, dedicated legal support which meant "DLC is the "jewel in the crown in the north" ... It's fantastic, brilliant" (Ingeus staff member).

- Clients do not always recognise the need for, or potential benefits of, legal support for employment issues they face so Ingeus' ability to 'spot' and refer potential cases facilitated access to legal support they might not otherwise have sought out. 
- Mental health issues can prevent individuals seeking support through self-referral so establishing the pathway between Ingeus and JiT reduced this potential barrier as employment advisers could allay concerns and provide reassurance.

- $\quad$ DLC involvement in a case sometimes catalysed employer action by acting as a "warning shot across the bow" that enables things to go "more smoothly" (Ingeus staff member) once employers are aware that legal advice has been given.

- Early intervention means positive outcomes can be achieved more quickly and easily and reduce the risk of more entrenched employment or clinical issues emerging. One external stakeholder suggested speedier resolution of employment issues can potentially lead to reductions in the length of work-related stress; avoidance of long-term unemployment where individuals are supported into work; and potentially "huge" (Derbyshire Public Health) savings to the public purse although acknowledged these are difficult to evidence. 


\section{Outcomes achieved: client assessment}

\subsection{Introduction}

This chapter examines the outcomes reported by clients receiving support from the JiT project who were interviewed as part of the evaluation. The extent to which clients' employment-related legal issues were resolved and employment outcomes achieved is discussed, as well as outcomes around health and well-being. It then reflects on any other outcomes achieved and the extent to which outcomes have been achieved over and above what might have happened if the project had not been in place.

\subsection{Employment outcomes}

As a result of the advice and support received from the DLC, a number of clients experienced positive employment outcomes and stated they were happy with the support and advice received from DLC and that it had improved their situation at work:

- Example 1: One client was supported by DLC to set up a meeting with HR and their manager and on how to approach this and what to discuss i.e., to discuss a phased return to work. This meeting helped them to return to work on a phased return after five months off sick. The client had been signed off work due to longterm depression and had felt under pressure to go back to work before they were ready. Without the support from DLC they would not have known how to approach their employer and would likely have been forced to go back to work when they were not fit to do so, and their mental state become much worse. The support from DLC helped to improve their work situation as they are now getting all the support they need to return to work. They now have a better dialogue with their employer and have been able to negotiate which shifts they will work:

“...they explained to me my rights...because technically l'm now classed as [having depression] which is classed as a disability and I never knew that and they said that [work] have got to put things in place for your return to work and make things easier for you". (JiT client)

- Example 2: A client who was off work with depression received advice from DLC about returning to a different type of role. DLC drafted a letter for the client to send to their employer and the result was the client returned to work much more quickly than they would have done without the support. 
"They [their employer] got back to [DLC] really really quick and I was back in work within at least two weeks after that letter had gone out". (JiT client)

- Example 3: DLC advised one client on medical leave what to say to HR and their manager and how to handle their situation at work. The client wrote to HR themselves and is now back at work after all issues were resolved.

A small number of clients decided not to pursue the advice they were given as they felt that doing so would have made their situation at work more difficult. For example, one client explained that although DLC had advised them that they had grounds to take out a grievance, they decided not to do so, questioning whether pursuing this route would change things for the better at work. The advice received was perceived as helpful, however, as they now knew they would be within their rights to take out a grievance at work if they ever felt this was necessary.

Some clients interviewed did not qualify for full support from DLC (see Chapter 5 above) and therefore did not manage to find a resolution to their employmentrelated legal issues. For some, this was due to the area that they lived in (restricted by project funding) or due to too much time having passed to appeal or raise a grievance.

One client who could not access full support has since been dismissed from work and has signed up with temping agency. They felt that the main consequence of not being able to get fuller support from the project (they had an initial discussion with DLC) was that they did not have a representative to attend meetings with them (they were also not in a union at the time). They felt very alone and isolated and found the whole process very difficult to manage. On reflection they felt that if they had been able to access the JiT project fully, they would have had a representative for meetings and would have been a lot more knowledgeable about the process.

A couple of clients who had not returned to their employer were informed too much time had passed to raise a grievance:

- Example 1: One client was told they had gone over the time for appealing and felt forced to hand in their notice:

"[DLC] rang me in the first instance. However, by that time l'd already ran over the time for appealing it with the final decision at work and I explained that, and I was...forced to give my notice in. It was no fault of Derbyshire Law, my previous work were just being awkward with me and quite intimidating". (JiT client)

- Example 2: Another client was told there was not enough of a case against their employer, and they were made redundant. They explained that DLC had no direct client contact with their employer and had expressed that there were no grounds for arguing that they had been made redundant on the basis on their disability. DLC also explained that too much time had passed since the incident had occurred meaning they could no longer do anything:

"....when the lady reviewed it...all I remember hearing her say was unfortunately it's just too late, it's too late, this isn't going to apply, it's just too late now. But regardless of the timing, this has happened so am I just going to roll over just pretend its ok now...its contributed to my depression...it was just too late for me not just in time". (JiT client) 
A couple of clients indicated DLC could not help them with their issue because their cases were too complicated:

- Example 1: One client said they were told that the JIT project was a "light-touch service" and that their case was too complicated and that DLC could not really advise them much: "They just pointed me somewhere else. They kept saying that it sounded like my case was too hard, my case was too complicated". DLC advised them to go to ACAS or Citizens Advice, but they ended up getting legal advice through their household insurance policy which included some legal cover.

- Example 2: Another client had a specific query regarding their contract and certain terms around sick pay and what they thought they were entitled to while signed off from work. During this period, they discovered that their employer had advertised their job while they were still an employee. Unfortunately, DLC could not help them resolve their issue and they ended up handing in their notice:

“...they phoned me, I spoke to a lady and...she said they couldn't help me. She didn't understand why my contract would state that [sick pay] was dependant on the local government pension continuous service - she couldn't really help me further with that and in regards to my job being advertised while I was off sick, she said they shouldn't do that but that they can do that... what I gathered from the phone call was that there was nothing that I could have done about either of my issues... and that was the only contact I had with Derbyshire Law". (JiT client)

\subsection{Health and well-being outcomes}

The advice received from the DLC clarified things for some clients and helped to ease the concern and worry associated with their work situation. Clients were often "at a low point" and it was good to know that there was someone who could provide advice and support. One client described it as having "someone on her side":

"[lt] was very important cos obviously when you're feeling like that, when you are down, you don't really consider things fully, but with their help it made it a lot easier". (JiT client)

Another client, who responded to the follow-up survey, said an important benefit of the support they received was:

"To be listened to and my being told my situation is real not in my head". (JiT client)

Having one less thing to worry about also had a positive influence on mental well-being in some cases. One client described how JIT had taken an element of the worry off them and the advice received had helped with their anxiety:

"I think [the project] has helped because it's taken an element of worry off that would have still been there... its removed an element of anxiety that would otherwise have certainly been there". (JiT client)

Another client explained that the JiT project had impacted positively on their mental health as they now knew where their stood legally with their employer and the advice had been instrumental in helping them to look at things from a different perspective:

"there's somebody there to listen to you...because I could have gone in there and just gone a bit daft...that's what I was fearing, going there and having that meeting and basically losing my head...they helped me to calm the situation...". (JiT client) 
While this client still struggled a lot with their mental health and they were unable to return to work, they explained that their work situation was not the sole contributing factor and that the advice they received from JiT had had a positive impact as they now knew not to resign without receiving what they were entitled to (they did not know they were entitled to notice pay).

The advice received about how to approach employers and what to say also gave a number of clients the confidence to contact or speak to their employer which they would have struggled to do otherwise because of their mental health. Being supported to contact their employer helped some clients to feel better about their situation at work and themselves.

\section{For those who were able to resolve their employment issues through the advice} received from JiT, their mental health often improved significantly as a result:

"it got me back to work within two weeks and it's made me feel a lot happier...I can actually go back to work, I can actually get myself out and feel like I'm doing something now because before, just sitting at home and that, I wasn't really doing [any physical activity] when I was off work, I was just like moping around at home'. (JiT client)

It was also the case for some clients that leaving their place of employment to take up another position or begin applying for other jobs, reduced the stresses associated with their old job and was the best outcome for their mental health.

\subsection{Other outcomes}

There was evidence that a couple of clients' financial situation improved as a result of the advice they received from the JiT project.

"The letter resolved everything. I was getting paid statutory sick pay as well throughout and the company who I work for, it went all a bit, all the wages got a bit messed up....and obviously with the furlough and everything they were taking $20 \%$ of everybody for furlough even if they were still working so they took $20 \%$ off me as well and with only being on statutory sick pay I ended up with nothing, I ended up with like minus figures... and that was all put in to the letter from Derbyshire Law and they ended up paying me the full amount so everything that was lost plus more...I end up getting a full wage because I was ready to go back to work...". (JiT client)

"They told me not to resign...because you've been there 11 years you'll get 11 weeks' notice pay and then to...try and come up with some kind of settlement like a good will gesture...about my pension, if there's any benefits I'm entitled to, any holiday pay l'm due...." (JiT client)

A respondent to the client follow-up survey also indicated their financial situation had improved as a consequence of support received from the project:

"Financially I received back the years pay I had lost". (JiT client)

By supporting clients to return to work, the JiT project may also have indirectly helped contribute to improved relationships. For example, one client who had received advice which facilitated their return to work explained that being back at work helped improve their relationships with their parents and in-laws:

"...my wife's parents kept saying like you need to get back to work and everything and if they can't get you anything you'll have to look at something else, so as soon 
as Derbyshire Law got involved, I was back at work within a couple of weeks so its improved [relationships] massively because l'm not getting grilled by my family and my wife's family anymore about getting back to work". (JiT client)

\subsection{Impact and value added}

Overall, most clients expressed that had they not been referred to the JiT project, they would have been very unlikely to have sought advice or support from elsewhere. Some assumed that the type of service offered by the JiT project had to be paid for and while several knew about solicitors that could help with legal issues, they were aware that this type of service was costly. Most did not have any prior knowledge that support existed to provide advice on employment issues and employment law. Some had sought advice through Citizens Advice either in the past or during the same time as accessing JiT but due to the long waiting times involved, this was not seen as a suitable option. For one client, when asked if they were aware of anywhere else, they could have sought advice or support from, they explained:

"No, I wasn't...and I would have been worse for it in terms of not being able to think about where to start...". (JiT client) 


\section{Lessons learnt and sustainability}

\subsection{Introduction}

There are number of lessons that can be drawn from the experience of JiT including those explicitly identified by clients and stakeholders as well as further lessons that can be suggested based on findings and evidence from elsewhere.

\subsection{Lessons}

\section{Engaging GPs}

While the pandemic had cut short engagement activities and scuppered plans to advertise JiT though leaflets and on screen in practices, DLC staff reflected that plans to generate referrals were "optimistic" and they "underestimated how much time and effort" it takes to generate GP referrals. Evidence from other evaluations ${ }^{7}$ shows that engaging GPs as a source of referrals for services that provide support around nonclinical issues can be challenging and time consuming. Ideally, securing buy-in requires time and commitment from a dedicated engagement officer; support from senior staff in key parts of the health system (Clinical Care Groups, Primary Care Networks and the Integrated Care System); a physical presence in practices such as regular 'clinics'; and the engagement and support of all practice staff including practise managers, GPs, nurses and administrative staff. Indeed, one external partner working in the health system reflected they could have done more to "sell strategically" JiT to health partners. A more comprehensive and intensive engagement process therefore needs to feature in any future programme that seeks to engage GPs.

At the same time, alternative referral options could be explored. While GPs remain a potentially valuable source of referrals and had been the "obvious choice" for JiT (Derbyshire Public Health staff member), primary care organisations have "millions" of other priorities and JiT may have been "lost" in a system with a clinical focus. Alternative, and potentially, better sources of referrals could include non-clinical services such as local authority services, housing providers, Jobcentres and community organisations. Social prescribing services continue to remain an option but would need to have a greater awareness and commitment to any future service that replaces JiT.

${ }^{7}$ The CRESR led evaluation of GMCAs Working Well Early Help has found difficulties in engaging some practices or individual GPs and securing referrals to the programme. 


\section{Continuous feedback}

Employment advisers in the main referral agency Ingeus highly valued JiT but were critical about the lack of a feedback process on client experiences and outcomes. This meant they only had partial view which relied on remaining in contact with clients and as noted above in section 5.3, led to some uncertainty about whether clients referred were eligible and the level of support received. Any future programme commissioned should consider, therefore, embedding a more robust feedback system. This would ensure that referral organisations are better placed to make appropriate referrals, provide complementary support to clients, and use positive experiences to encourage and inspire clients to take up support.

\section{Eligibility criteria}

The confusion over eligibility criteria, particularly in terms of those with trade union support or those living outside Chesterfield, needs to be addressed. Flexibility according to perceived need is welcome to accommodate more vulnerable clients and address any issues with the quality of alternative sources of support, but referral organisations need to be aware of the scope of flexibility. This will ensure appropriate referrals and confidence that individuals referred will receive the support required. Again, robust feedback mechanisms may help to reduce this uncertainty by eliminating the 'black box' of what happens once clients are referred.

\section{Delivery of support}

Many clients emphasised the positive impact of the advice they received on their wellbeing and felt fully listened to. A number of clients, however, found the service to be a bit impersonal and rushed, particularly those experiencing mental health difficulties. This suggests DLC may need to build on the valuable support they are already providing to caseworkers around mental health issues. The lifting of Covid-19 restrictions may also assist here as face-face contact becomes an option again, with some clients indicating this method of delivery would enable them to engage with support more effectively.

\section{Promotion of the service}

Quite a few clients said that they did not know what to expect from the JiT project and setting out what the service can offer more clearly and clarifying expectations would be beneficial. This could also help support those experiencing mental health difficulties. For example, one interviewee who was "under a lot of stress at the time" of referral provided the following recommendation via the client follow-up survey:

"I also would suggest an initial email is sent out to all applicants to advise on the 'terms and conditions' of being helped by the project - how much time is allocated, how will the interview with a legal expert take place, what information should I have ready when called by the expert, and really important, when will the applicant be contacted". (JiT client)

\section{Strategic alignment}

One stakeholder suggested that, with hindsight, JiT may have functioned better as a specialist pathway embedded within a broader strategic framework such as a wider determinants of health strategy. There would reduce the risk of becoming "forgotten [as an] isolated project", particularly within clinical service networks that might otherwise overlook a small project providing support around non-clinical issues. 


\subsection{Sustainability}

In terms of sustainability, all stakeholders interviewed suggested a need to sustain or recommission the service in some form beyond its current lifetime. This reflected the unanimous view among stakeholders that the service addressed a clear need, generated demonstratable impact, added value to existing mental health (IAPT) and employment (Ingeus) services, and endorsed the principle of early intervention. One adviser in a referral agency, for example, noted there is "absolutely a need" to sustain the project, especially in light of the scaling back of legal aid in recent years:

"If we didn't have DLC it could end badly. We would be stuffed. Advisers need to know there is something out there...DLC have been angels...I would get on my knee and grovel, that service needs to be cloned". (Ingeus staff member)

That most of the clients interviewed stated had they not been referred to the JiT project they would have been very unlikely to have sought advice or support from elsewhere, also indicates the project is addressing a clear gap in the provision of legal advice to those affected by health issues related to difficulties in their employment.

However, one external stakeholder cautioned that demonstrable qualitative benefits did not yet confirm its potential scope and capacity to operate at scale. Nevertheless, they saw value in trialling a wider rollout, particularly if wider economies of scale (e.g., shared back-office functions) could be achieved if commissioned within a wider strategy as part of a bigger system i.e., a series of programmes operating through wider determinants of health.

Options for future funding include from health bodies, particularly Public Health England, and/or other funds supporting people with health needs. 
i For example: Waddell, G and Burton, A K (2006) Is work good for your health and well-being?: https://assets.publishing.service.gov.uk/government/uploads/system/uploads/attachment data/file/21 4326/hwwb-is-work-good-for-you.pdf

iDepartment for Work and Pensions (DWP) and Department of Health and Social Care (DHSC) (2017) Thriving at work: The Stevenson / Farmer review of mental health and employers. https://assets.publishing.service.gov.uk/government/uploads/system/uploads/attachment data/file/65 8145/thriving-at-work-stevenson-farmer-review.pdf; DWP and DHSC (2017) Improving lives, op. cit.; The Mental Health Taskforce (2016) The Five Year Forward View for Mental Health. https://www.england.nhs.uk/wp-content/uploads/2016/02/Mental-Health-Taskforce-FYFV-final.pdf; NHS (2019) NHS Long Term Plan. https://www.longtermplan.nhs.uk/wp-content/uploads/2019/08/nhslong-term-plan-version-1.2.pdf; NHS England (2016) General Practice Forward View. https://www.longtermplan.nhs.uk/wp-content/uploads/2019/08/nhs-long-term-plan-version-1.2.pdf;

Public Health England (2017) Health profile for England: 2017.
https://www.gov.uk/government/publications/health-profile-for-england

iii Institute of Health Equity (2020) Health equity in England: The Marmot review 10 years on https://www.health.org.uk/sites/default/files/upload/publications/2020/Health\%20Equity\%20in\%20Engl and The\%20Marmot\%20Review\%2010\%20Years\%200n full\%20report.pdf

iv Good quality work is described as "characterised by features including job security; adequate pay for a healthy life; strong working relationships and social support; promotion of health, safety and psychosocial wellbeing; support for employee voice and representation; inclusion of varied and interesting work; a fair workplace; promotion of learning development and skills use; a good effortreward balance; support for autonomy, control and task discretion; and good work-life balance...Poor quality work is essentially work with the opposite of these features." Institute of Health Equity (2020) op cit., p61.

${ }^{\vee}$ For example: Benach, J. Vives, A., Amable, M., Vanroelen, C., Tarafa, G., \& Muntaner, C. (2014) Precarious Employment: Understanding an Emerging Social Determinant of Health. Annual Review of Public Health, 35(1), 229-253 and Julià, M., Vanroelen, C., Bosmans, K., Van Aerden, K., \& Benach, J. (2017). Precarious Employment and Quality of Employment in Relation to Health and Well-being in Europe. International Journal of Health Services, 47(3), 389-409.

vi Genn, H. (2019) When Law is Good for Your Health: Mitigating the social determinants of health through access to justice. Current Legal Problems, 72(1), pp.159-202.

vii Franklyn, R. Budd, T. Verrill, R. and Willoughby, M. (2017) Findings from the legal problem and resolution survey, 2014-15. Ministry of Justice.

viii Beardon, S., Woodhead, C., Cooper, S., Raine, R., \& Genn, H. (2020) Health-justice partnerships: innovation in service delivery to support mental health. Journal of Public Mental Health. 


\section{Sheffield Hallam University}

Just in Time Evaluation Report

CRISP, Richard <http://orcid.org/0000-0002-3097-8769>, GILBERTSON, Janet

<http://orcid.org/0000-0003-3338-7590>, SANDERSON, Elizabeth < http://orcid.org/00000003-1423-1670> and WOODWARD, Abi

Available from the Sheffield Hallam University Research Archive (SHURA) at:

http://shura.shu.ac.uk/29410/

\section{Copyright and re-use policy}

Please visit http://shura.shu.ac.uk/29410/ and http://shura.shu.ac.uk/information.html for further details about copyright and re-use permissions. 